\title{
Treatment outcomes of COVID-19 patients in bi-disciplinary cardiology and cardiac surgery ward
}

\author{
Mariusz Wójcik', Adam Gąsior'1, Jakub Karpiak', Marcin Chlebuś1, Janusz Romanek¹,2, Marcin Rak³, \\ Maciej Kolowca ${ }^{2,3}$, Kazimierz Widenka ${ }^{2,3}$, Andrzej Przybylski ${ }^{1,2}$ \\ ${ }^{1}$ Clinical Department of Cardiology with the Acute Coronary Syndromes Subdivision, Clinical Provincial Hospital no. 2 in Rzeszow, Poland \\ ${ }^{2}$ Faculty of Medicine, University of Rzeszow, Poland \\ ${ }^{3}$ Clinical Department of Cardiac Surgery, Clinical Provincial Hospital no. 2 in Rzeszow, Poland
}

\author{
Correspondence to: \\ Mariusz Wójcik, MD, \\ Clinical Department of Cardiology \\ with the Acute Coronary \\ Syndromes Subdivision, \\ Clinical Hospital no. 2 in Rzeszow, \\ Lwowska 60, 35-301 Rzeszów, \\ Poland, \\ phone: +48 178664455 , \\ e-mail: \\ mariuszwojcik88@gmail.com \\ Copyright by the Author(s), 2022 \\ DOI: 10.33963/KP.a2021.0194 \\ Received: \\ September 17, 2021 \\ Accepted: \\ December 29, 2021 \\ Early publication date: \\ December 30, 2021
}

\section{INTRODUCTION}

SARS-CoV-2, a coronavirus causing severe acute respiratory syndrome, emerged at the end of 2019 and triggered a pandemic forcing rapid changes in the organization of public healthcare both at the national and in-hospital level [1]. Patients infected with COVID-19 underwent treatment in designated hospitals and other existing facilities with infectious diseases departments.

Patients with either exacerbation of chronic heart disease or patients recently affected by acute cardiac disorders are at high risk of death if infected with SARS-CoV-2 [2]. Unfortunately, in Poland, some COVID-19 designated hospitals do not have medical facilities to conduct highly specialized cardiological therapies. A transfer to COVID-19 dedicated cardiology or cardiac surgery units reduces an opportunity to achieve optimal medical outcomes [3]. Depending on available healthcare resources, urgent cardiac procedures with documented efficacy should be continued during consecutive waves of the COVID-19 pandemic [4]. To provide prompt treatment and diminish the risk of the virus spread, our hospital, which is a multi-specialist non-COVID-19 dedicated hospital, established a combined unit for COVID-19 patients. The ward functioned for 6 months (from October 23, 2020 to October 23,2021 ) during the 2 waves of the highest intensity of the pandemic in Poland.

The study aims to present the clinical characteristics, the course of hospitalization, outcomes, and risk factors of death among our patients.

\section{METHODS}

The cases comprised 227 patients hospitalized in the newly created ward for exacerbation of chronic cardiovascular diseases or acute illnesses and requiring urgent cardiac surgery or cardiac invasive procedure. Patients were diagnosed with COVID-19 in accordance with the recommendations of the Polish Association of Epidemiologists and Infectiologists with the use of the real-time polymerase chain reaction method [5]. Others who tested negative on admission were hospitalized separately and tested regularly twice a week or in case of any infection symptoms.

Patients were hospitalized for acute heart failure (New York Heart Association [NYHA] class III or IV), acute coronary syndrome, pulmonary embolism, infective endocarditis, arrhythmia, hypertension crisis, myocarditis, pericarditis, a need for urgent cardiac surgery, post-sternotomy complication treated with vacuum-assisted closure (VAC) therapy, or pneumonia in patients with multiple cardiovascular comorbidities. There were no exclusion criteria.

Both risk factors and cardiovascular diseases were identified based on a medical history of prior diagnosis or treatment and defined according to the current European Society of Cardiology guidelines [6].

Blood samples were drawn on admission using a minimal stasis and atraumatic venipuncture from an antecubital vein.

Left ventricular ejection fraction was assessed using transthoracic echocardiography and the biplane Simpson method with Philips 
Table 1. Demographic and clinical characteristics of the studied groups

\begin{tabular}{|c|c|c|c|c|}
\hline Variable & $\begin{array}{l}\text { All patients } \\
(n=227)\end{array}$ & Survivors $(n=179)$ & Non-survivors $(n=48)$ & $P$-value \\
\hline Age, years & $69.6(13.4)$ & $68.5(13.7)$ & $73.4(11.8)$ & 0.028 \\
\hline Male sex, n (\%) & $150(66)$ & $115(64)$ & $35(73)$ & 0.26 \\
\hline Body mass index, $\mathrm{kg} / \mathrm{m}^{2}$ & $30.3(6.2)$ & $31.0(6.5)$ & $28.1(4.4)$ & 0.069 \\
\hline Length of hospital stay, days & $14(9-22)$ & $14(11-22)$ & $13(6-21)$ & 0.12 \\
\hline Left ventricular ejection fraction, $\%$ & $50(35-56)$ & $50(40-60)$ & $40(20-48)$ & 0.003 \\
\hline \multicolumn{5}{|l|}{ Main cause of hospitalization, $\mathrm{n}(\%)$} \\
\hline Acute coronary syndrome $\mathrm{a}^{\mathrm{a}}$ & $64(28)$ & $46(26)$ & $18(38)$ & 0.11 \\
\hline Heart failure & $58(26)$ & $45(25)$ & $13(27)$ & 0.78 \\
\hline Pulmonary embolism & $13(6)$ & $10(6)$ & $3(6)$ & 0.74 \\
\hline Infective endocarditis & $11(5)$ & $7(4)$ & $4(8)$ & 0.25 \\
\hline Arrhythmia $^{\mathrm{b}}$ & $26(11)$ & $23(13)$ & $3(6)$ & 0.2 \\
\hline Hypertension & $6(3)$ & $6(3)$ & $0(0)$ & 0.35 \\
\hline Urgent cardiac surgeryc & $17(7)$ & $17(9)$ & $0(0)$ & 0.027 \\
\hline Pneumonia & $30(13)$ & $23(13)$ & $7(15)$ & 0.75 \\
\hline Peri/Myocarditis & $2(1)$ & $2(1)$ & $0(0)$ & 1.00 \\
\hline \multicolumn{5}{|l|}{ Risk factors and comorbidities, n (\%) } \\
\hline Diabetes mellitus & $76(33)$ & $55(30)$ & $21(44)$ & 0.09 \\
\hline Arterial hypertension & $158(70)$ & $127(71)$ & $31(65)$ & 0.39 \\
\hline Heart failure & $109(48)$ & $84(47)$ & $25(52)$ & 0.53 \\
\hline Coronary artery disease & $49(22)$ & $34(19)$ & $15(31)$ & 0.07 \\
\hline Atrial fibrillation & $95(42)$ & $69(39)$ & $26(54)$ & 0.051 \\
\hline Cardiac pacing & $16(7)$ & $13(7)$ & $3(6)$ & 1.00 \\
\hline Rheumatic disorder & $12(5)$ & $10(6)$ & $2(4)$ & 1.00 \\
\hline Obesity & $60(26)$ & $48(27)$ & $12(25)$ & 0.80 \\
\hline Pulmonary disease & $9(4)$ & $7(4)$ & $2(4)$ & 1.00 \\
\hline \multicolumn{5}{|l|}{ Laboratory parameters on admission } \\
\hline Hemoglobin, g/dl & $12.76(2.25)$ & $12.82(2.22)$ & $12.56(2.39)$ & 0.49 \\
\hline Platelets, $10^{9} / \mathrm{I}$ & $198(142-261)$ & $204(153-264)$ & $169(117-239)$ & 0.015 \\
\hline White blood cells, $10^{9} / /$ & $7.1(5-9.8)$ & $6.8(4.7-9.1)$ & $8.8(6-13.8)$ & 0.002 \\
\hline Creatinine, $\mu \mathrm{mol} / \mathrm{l}$ & $86.2(67.4-120.3)$ & $82.2(65.0-109.6)$ & $109.6(81.8-150.8)$ & $<0.001$ \\
\hline $\mathrm{hsCRP}, \mathrm{mg} / \mathrm{l}$ & $39(13-87)$ & $29(9-66)$ & $86(44-154)$ & $<0.001$ \\
\hline Maximum hsCRP, mg/l & $67(24-131)$ & $49(17-108)$ & $128(84-187)$ & $<0.001$ \\
\hline Procalcitonin, ng/ml & $0.14(0.07-0.42)$ & $0.1(0.06-0.24)$ & $0.35(0.15-1.38)$ & $<0.001$ \\
\hline NT-pro-BNP, pg/ml & $4018(985-13273)$ & $2720(701-6586)$ & $12974(4510-35000)$ & $<0.001$ \\
\hline hsTnl, ng/l & $73(19-754)$ & $43(14-463)$ & $585(116-7316)$ & $<0.001$ \\
\hline D-dimer, ng/ml & $1165(652-5303)$ & $1008(570-3652)$ & 3381 (1160-19943) & $<0.001$ \\
\hline $\mathrm{TSH}, \mathrm{mlU} / \mathrm{l}$ & $1.08(0.48-1.88)$ & $1.1(0.54-1.9)$ & $0.92(0.28-1.51)$ & 0.089 \\
\hline \multicolumn{5}{|l|}{ Therapy, n (\%) } \\
\hline Noninvasive oxygen therapy & $125(55)$ & $101(56)$ & $24(50)$ & 0.51 \\
\hline Mechanical ventilation $>24$ hours & $21(9)$ & $1(1)$ & $20(42)$ & $<0.001$ \\
\hline Antiplatelet therapy & $92(41)$ & $71(40)$ & $21(44)$ & 0.61 \\
\hline Anticoagulants & $191(84)$ & $147(82)$ & $44(92)$ & 0.11 \\
\hline$\beta$-blockers & $179(79)$ & $149(83)$ & $30(63)$ & 0.002 \\
\hline ACEIs/ARBs & $125(55)$ & $109(61)$ & $16(33)$ & $<0.001$ \\
\hline Statin & $120(53)$ & $97(54)$ & $23(47)$ & 0.44 \\
\hline Antibiotics & $140(62)$ & $97(54)$ & $43(90)$ & $<0.001$ \\
\hline Steroids & $122(54)$ & $92(51)$ & $30(63)$ & 0.17 \\
\hline Convalescent plasma & $17(7)$ & $11(6)$ & $6(12)$ & 0.21 \\
\hline Remdesivir & $64(28)$ & $50(28)$ & $14(29)$ & 0.87 \\
\hline \multicolumn{5}{|l|}{ Procedure during hospitalization, $\mathrm{n}(\%)$} \\
\hline Coronary angiography & $83(37)$ & $64(36)$ & $19(40)$ & 0.62 \\
\hline $\mathrm{PCl}$ & $54(24)$ & $41(23)$ & $13(27)$ & 0.54 \\
\hline CIEDs implantation & $11(5)$ & $11(6)$ & $0(0)$ & 0.13 \\
\hline Temporary cardiac pacing & $3(1)$ & $1(1)$ & $2(4)$ & 0.11 \\
\hline CIEDs removal & $3(1)$ & $2(1)$ & $1(2)$ & 0.51 \\
\hline Cardiac ablation & $4(2)$ & $4(2)$ & $0(0)$ & 0.58 \\
\hline Cardiac surgeryc & $20(9)$ & $20(11)$ & $0(0)$ & 0.009 \\
\hline
\end{tabular}

Values are given as mean (standard deviation [SD]), number (percentage), or median (interquartile range [IQR])

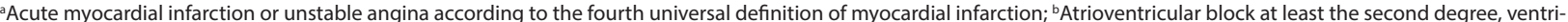

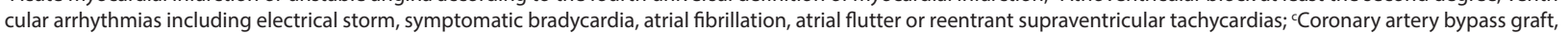
valve repair or replacement, ascending aortic replacement, thoracic endovascular aortic repair, transcatheter valve implantation or VAC therapy

Abbreviations: ACEIs, angiotensin-converting enzyme inhibitors, ARBs, angiotensin receptor blockers; CIEDs, cardiac implantable electronic devices; hsCRP, high-sensitivity C-reactive protein; hsTnl, high-sensitivity troponin I; NT-pro-BNP, N-terminal prohormone of brain natriuretic peptide; PCl, percutaneous coronary intervention; TSH, thyroidstimulating hormone 
Affiniti CVx (Philips Healthcare, Amsterdam, The Netherlands).

The analyzed endpoint in our study was in-hospital mortality from any cause. We have also analyzed the need for oxygen supplementation i.e. non-invasive oxygen therapy (including Optiflow ${ }^{\circledast}$ High Flow Nasal system), mechanical ventilation, duration of hospital stay, use of cardiovascular drugs grouped into drug classes ( $\beta$-blockers, angiotensin-converting enzyme inhibitors/angiotensin receptor blockers [ACEls/ARBs], statins, anticoagulation treatment, and antiplatelet therapy), and other recommended therapy (steroids, antibiotics, convalescent plasma, and remdesivir) [7]. The last part of Table 1 summarizes invasive procedures performed throughout the hospitalization.

\section{Statistical analysis}

Statistical analysis was performed using PQStat v.1.8.2. Software (Poznań, Poland). Continuous variables are presented as a mean and standard deviation if parametric (assessed using the Shapiro-Wilk test) or as a median and interquartile range (IQR) for continuous variables. Categorical variables are presented as numbers and percentages. The $X^{2}$ test, Fisher's exact test, Student's t-test, and the Mann-Whitney U-test were used, as appropriate, for group comparison. The univariate logistic regression was applied to assess predictors of in-hospital death or mechanical ventilation. The results were presented as odds ratio (OR) with 95\% confidence intervals $(\mathrm{Cl})$. A two-sided $P$-value of $<0.05$ was considered statistically significant.

\section{RESULTS AND DISCUSSION}

Demographic and clinical characteristics of survivors and non-survivors are presented in Table 1. From October 23 to April 23227 patients were admitted to the bi-disciplinary cardiology and cardiac surgery ward and completed their hospital course (i.e. discharge or death). Most of the cases were tested positive on the first day of hospitalization (median [IQR], 1 [1-4] day), hence they were defined as community-acquired infections. The median hospitalization duration was 14 (9-22) days. Overall, in-hospital mortality was $21 \%$ (48 of 227 patients). Seventy-nine percent of non-survivors were older than 65 years (38 of 48 patients). There was no difference between the survivor and non-survivor groups with respect to sex (17\% in female vs $23 \%$ in male; $P>0.05$ ), the body mass index, and the duration of hospital stay (Table 1). Reduced left ventricular ejection fraction was observed in the non-survivor group.

There were no intergroup differences regarding the main cause of hospitalization. The most frequent reasons for hospitalization were acute coronary syndromes (28\%), acute heart failure (26\%), and pneumonia (13\%) in patients with multiple cardiovascular comorbidities. The most prevalent cardiovascular risk factor or disease was arterial hypertension (70\%), followed by heart failure (48\%), atrial fibrillation (42\%), diabetes mellitus (33\%), obesity (26\%), and coronary artery disease (22\%). Seven percent of patients had a cardiac pacemaker or implantable cardioverter defibrillator previously implanted.

Our data confirm that elderly patients with numerous comorbidities are at the highest risk of hospitalization [8].

Non-survivors had a higher level of troponin I, N-terminal prohormone of brain natriuretic peptide, white blood cells count, creatinine, D-dimer, C-reactive protein, and procalcitonin on admission than survivors. $\beta$-blockers and ACEls/ARBs were used more frequently by survivors than by non-survivors. By contrast, antibiotics were used less frequently by survivors than by non-survivors. No difference amongst the groups was observed regarding using steroids, convalescent plasma, or remdesivir.

Oxygen supplementation was necessary for $64 \%$ of patients $(n=146)$. Mechanical ventilation ( $>24$ hours to exclude resuscitation and perioperative period) was applied in 21 cases (9\%). Nasal high-flow oxygen therapy (including prone position) was applied in the preceding stage of invasive ventilation and also in 26 patients (11\%). The mortality rate was high in patients requiring mechanical ventilation (95\%).

Age over 65 years (OR, 2.33; 95\% Cl, 1.09-4.97; $P=0.029)$ and ejection fraction $<50 \%(\mathrm{OR}, 3.94 ; 95 \% \mathrm{Cl}, 1.9-8.18$; $P<0.001)$ were independent predictors of in-hospital death, whereas treatment with ACEIs/ARBs (OR, 0.32; 95\% $\mathrm{Cl}, 0.16-0.62 ; P<0.001)$ or $\beta$-blockers (OR, $0.34 ; 95 \% \mathrm{Cl}$, $0.17-0.68 ; P=0.002$ ) were associated with a lower risk of in-hospital death and mechanical ventilation (OR, 0.16; $95 \% \mathrm{Cl}, 0.05-0.5 ; P=0.002$ and $\mathrm{OR}, 0.31 ; 95 \% \mathrm{Cl}, 0.12-0.79$; $P=0.014$, respectively).

The most frequently performed procedures were coronary angiography in 83 patients (37\%), percutaneous coronary intervention in 54 patients (24\%), and cardiac surgery in 20 patients (9\%), most of whom underwent coronary artery bypass grafting or valve replacement/repair procedure (75\%). It is worth noting that there were no deaths among patients in the cardiac surgery group.

Our study presents data of the unique group of patients both with SARS-CoV-2 infection and acute cardiac disorders or exacerbation of chronic heart diseases treated in a bi-disciplinary unit of the multi-profile tertiary referral hospital that was not solely dedicated to COVID-19 patients. Establishing such a department made it possible to effectively separate infected patients from healthy ones and to maintain access to highly specialized procedures.

\section{Article information}

Conflict of interest: None declared.

Open access: This article is available in open access under Creative Common Attribution-Non-Commercial-No Derivatives 4.0 International (CC BY-NC-ND 4.0) license, allowing to download articles and share them with others as long as they credit the authors and the publisher, but without permission to change them in any way or use them commercially. For commercial use, please contact the journal office at kardiologiapolska@ptkardio.pl. 


\section{REFERENCES}

1. Gąsior M, Gierlotka M, Tycińska A, et al. Effects of the coronavirus disease 2019 pandemic on the number of hospitalizations for myocardial infarction: regional differences. Population analysis of 7 million people. Kardiol Pol. 2020; 78(10): 1039-1042, doi: 10.33963/KP.15559, indexed in Pubmed: 32820878.

2. Gerotziafas GT, Catalano M, Colgan MP, et al. Scientific Reviewer Committee. Guidance for the management of patients with vascular disease or cardiovascular risk factors and COVID-19: position paper from VAS-European Independent Foundation in Angiology/Vascular Medicine. Thromb Haemost. 2020; 120(12): 1597-1628, doi: 10.1055/s-0040-1715798, indexed in Pubmed: 32920811.

3. Bryndza MA, Litwinowicz R, Bartuś S, et al. Incidence of mechanical complications following myocardial infarction during the first two months of the COVID-19 pandemic in the Southern Poland region: a multicenter study. Kardiol Pol. 2021; 79(1): 66-68, doi: 10.33963/KP.15653, indexed in Pubmed: 33094570.

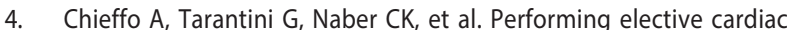
invasive procedures during the COVID-19 outbreak: a position state- ment from the European Association of Percutaneous Cardiovascular Interventions (EAPCI). Eurolntervention. 2021; 16(14): 1177-1186, doi: 10.4244/EIJ-D-20-01291, indexed in Pubmed: 33416050.

5. Flisiak R, Horban A, Jaroszewicz J, et al. Management of SARS-CoV-2 infection: recommendations of the Polish Association of Epidemiologists and Infectiologists as of March 31, 2020. Pol Arch Intern Med. 2020; 130(4): 352-357, doi: 10.20452/pamw.15270, indexed in Pubmed: 32231173.

6. European Society of Cardiology. Guidelines and Scientific Documents. Available online: www.escardio.org [Access: September 16, 2021].

7. Flisiak R, Horban A, Jaroszewicz J, et al. Management of SARS-CoV-2 infection: recommendations of the Polish Association of Epidemiologists and Infectiologists. Annex no. 1 as of June 8, 2020. Pol Arch Intern Med. 2020; 130(6): 557-558, doi: 10.20452/pamw.15424, indexed in Pubmed: 32529822.

8. NowakB, Szymański P, Pańkowski l, et al. Clinical characteristics and shortterm outcomes of patients with coronavirus disease 2019: a retrospective single-center experience of a designated hospital in Poland. Pol Arch Intern Med. 2020; 130(5): 407-411, doi: 10.20452/pamw.15361, indexed in Pubmed: 32420710. 